\title{
Asteroid hazards stir up defence debate
}

Boston. After last summer's fiery collision between Comet Shoemaker-Levy 9 and the planet Jupiter, concern about the potential impacts from large asteroids and comets is continuing to grow. Next week, an international conference of astronomers, planetary scientists and weapons specialists takes place at the Lawrence Livermore National Laboratory in California, to assess ways of defending the Earth from potentially devastating impacts.

The conference comes on the heels of a meeting in April, at which scientists and officials of the United Nations in New York discussed the hazards posed by near-Earth objects (NEOs) and ways to identify and track them. This itself was a follow-up to workshops sponsored by the US National Space and Aeronautics Administration (NASA) in 1991, which culminated in the January 1992 Spaceguard Survey report.

David Morrison, an astronomer at the NASA Ames Research Center in California, who chaired the 1991 sessions, told the UN meeting that a comprehensive search was needed for Earth-crossing asteroids and comets as outlined in the Spaceguard proposal. He claimed that a coordinated, international network of telescopes to carry out this survey would be "a good investment", considering that a major impact could kill millions of people.

"Right now, there are fewer than a dozen people searching for NEOs worldwide, fewer people than it takes to run a single McDonald's," says Morrison. That effort, he said, should be compared to the fact that the average annual risk of death from cosmic

bombardment is comparable to an individual's risks of dying in a plane crash.

Many claim that recent advances in charge-coupled device detectors and computers mean that a survey could be accomplished more quickly than the 25-year, \$300-million Spaceguard plan. Ted Bowell, an astronomer at the Lowell astronomer, told the UN meeting that an updated system might complete the job in about 10 years, and for about half the cost. "The whole thing could be done for the cost of a [cheap] space mission," he says.

John Remo, a physicist who organized the UN meeting, is working with the UN to ensure that the defensive aspects of such a programme, if approved, conform with international law over the use of military weapons in space.

A set of policy recommendations drawn up by Remo and approved by most conference participants has already won preliminary support from the UN Office of Outer Space Affairs. These call for the establishment of "adequate observational facilities" in both the northern and southern hemispheres, a mechanism for sharing information on potentially threatening NEOs, and broad international agreement before responding to such a threat.

$\mathrm{He}$ is planning to take a draft of the recommendations to next week's workshop at Livermore which is being sponsored by bodies ranging from NASA and the US Air Force Space Command to various Russian energy agencies.

According to Gregory Canavan, a physicist at Los Alamos who is one of the event's

\section{Nuclear storage decision postponed}

London. The British government has postponed plans to build an underground nuclear waste repository close to the Sellafield nuclear fuel reprocessing plant in northern England "until at least the latter half of the next century".

Construction of the $£ 2$-billion (US\$3.2billion) depository, designed to house lowand intermediate-level nuclear waste which remains radioactive for several thousand years, was expected to begin by 2005 . But John Gummer, Secretary of State for the Environment, announced last week that building work on the structure, to be sited 650 metres below ground, will not begin before the year 2060 .

"We are aware of the concern expressed by environmental groups and others," Gummer said in a written reply to a question in parliament which coincided with the government's announcement of its plans to sell off parts of the nuclear industry to the private sector. "Options available to future generations should not be foreclosed by irre- versible action taken now," he said. A spokesman for the Department of the Environment (DoE) later added that the repository might be built even later than 2060 , if the government chose to locate it at a site other than Sellafield.

Safe storage of nuclear waste is the responsibility of UK Nirex Limited, which is jointly owned by British Nuclear Fuels, Nuclear Electric, the UK Atomic Energy Authority and Scottish Nuclear. Attempts at a solution have been dogged by controversy and delays leading to mounting bills - and accumulating waste. Nirex has already spent two years and $£ 50$ million investigating 500 possible sites in the United Kingdom.

A white paper on radioactive waste management is expected later this summer. But a DoE spokesman said the decision to put off building the repository was released one month ahead of schedule to reassure potential investors in nuclear power that they would not be saddled with the job of disposing of nuclear waste.

Ehsan Masood chief coordinators, the conference is intended to complement the UN conference. "We're trying to integrate detection and mitigation [or defense] technologies to make sure that both approaches will be compatible," Canavan says. "In the past, people really haven't connected the two."

Canavan says the Livermore conference will not propose an actual defensive system. "We're hoping to define the problem in sufficient detail to identify the key technological components that will be needed, along

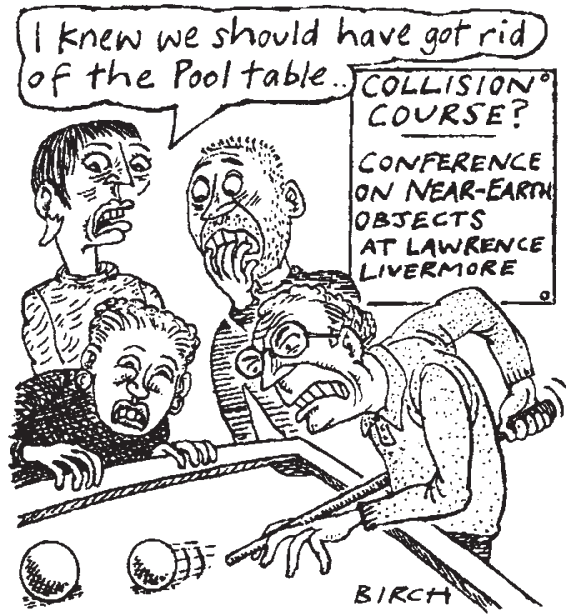

with their weaknesses, so that a few years from now we could put together a detailed design."

In the interim, he says, experiments could determine the strength of meteoritic materials, to "give us a sense of how hard you could push an object without breaking it up". 'Coupling' experiments, aimed at finding efficient ways of delivering energy to threatening NEOs, are also needed, he says.

Canavan says that an effective defensive solution will not be a single system, but will require a "grab bag" of techniques whose efficacy will depend on the size of the approaching asteroid or comet, and the time remaining before a projected collision.

Given time to prepare, one option might be to set up a huge 'sail' on the NEO to perturb its orbit, or to install solar cells that would power 'ion thrusters'. But Canavan says that, for a big object close at hand, nuclear explosions may be the only viable option.

But the idea of putting nuclear weapons in space remains highly controversial (as, indeed, does the whole idea of funding a major observation/defense programme, which some critics claim would be an inappropriate allocation of resources).

Such a measure would violate both the 1963 Limited Test Ban Treaty and the 1967 Outer Space Treaty. "The last thing we want to do is trigger another nuclear arms race on account of near-Earth objects," says Remo. "That would create a peril far greater than the NEOs themselves."

Steve Nadis 